\title{
Birziklatutako poliuretano-aparraren erabilera nahaste bituminosoetan
}

\section{(Employment of recycled polyurethane foam in bituminous mixes)}

\author{
Heriberto Pérez-Acebo ${ }^{1 *}$, Miguel Ángel Salas ${ }^{2}$ \\ ${ }^{1}$ Ingeniaritza Mekanikoa Saila. Bilboko Ingeniaritza Eskola (UPV/EHU) \\ ${ }^{2}$ Universidad de Burgos, Burgos
}

LABURPENA: Substantzia asko erabili izan dira betuna eraldatzeko, bere propietateak eta errendimendua hobetzeko helburuarekin, baina gehien erabiltzen direnak polimeroak dira. Poliuretano-aparra isolatzaile termikoak fabrikatzeko prozesuan sortzen den hondakin-produktu bat da, normalean zabortegietan amaitzen duena. Poliuretano-apar hondakina betun eraldatzaile gisa aukeratu zen, betunak eraldatzeko bi nahaste bituminoso ekoizteko: beroan egindako nahastea, B 50/70 motako betunarekin, eta mastika bituminosoa, B 35/50 motako betunarekin. Hainbat polimero (poliuretano-apar) kantitate gehitu ziren, betunaren pisuaren $\%$ letik \% 5era bitartean. Betun bietan ikusi zen polimeroa \% 5ean baino gehiagoan sartzeak zakar bihurtzen zituela laginak, gehiegi murrizten baitzuen langarritasuna. Polimeroa \% 4an zuten bi nahaste bituminosoz eginiko laginak ekoiztu ziren. Marshall entseguak egonkortasunean hobekuntzak eta deformazio txikiagoa erakutsi zituen eraldatutako beroan egindako nahaste bituminosoetan, eraldatu gabeko laginekin konparatzean. Era berean, eraldatutako mastika bituminosoak indentazio-balio txikiagoak erakutsi zituen eraldatu gabeak baino, trafiko astuneko errepideetan erabiltzeko gai izanik. Ondorioz, poliuretano-apar hondakina etorkizun handiko betun eraldatzailea izan daitekeela atzematen da, hobetu egiten baititu betunaren propietateak.

HITZ GAKOAK: poliuretano-apar hondakina, birziklatutako materiala, betun eraldatzailea, beroan egindako nahastea, mastika bituminosoa, polimeroz eraldatutako betuna.

\begin{abstract}
Many substances have been used to modify bitumens with the aim of enhacing their properties and performance, but the most widely used are the polymers. Polyurethane foam is a by-product from themal insulation industry, which is frequently deposited in landfills. Waste polyurethane foam was selected as a possible bitumen modifier in bitumens to produce two different bituminous mixes: hot mix asphalts with a B 50/70 bitumen and mastic asphalt with B 35/50 bitumen. Different quantities of polymer were added to the bitumens, from $1 \%$ to $5 \%$ in weight of the bitumen. Mixes with $5 \%$ or more of polymer content were discarded as they became rough and had low workability. Thus, specimens of both bituminous materials were produced with $4 \%$ of polymer. The Marshall test showed that modified hot mix asphalt obtained improvements in stability and a lower deformation when compared to non-modified mixtures. Similarly, the modifed mastic asphalts showed lower indentation values than non-modified samples, being able to be employed in road with heavy traffic. Consequently, the waste polyurethane foam resulted in a promising bitumen modifier that enhances bitumen properties.
\end{abstract}

KEYWORDS: waste polyurethane foam, recycled material, bitumen modifier, hot mix asphalt, mastic asphalt, polymer modified bitumen.

\footnotetext{
* Harremanetan jartzeko / Corresponding author: Heriberto Pérez-Acebo, Ingeniaritza Mekanikoa Saila, Bilboko Ingeniaritza Eskola. Rafael Moreno «Pitxitxi» pasalekua, 2 (48013 Bilbao). - heriberto.perez@ehu.eus - https://orcid.org/00000003-0577-9597.

Nola aipatu / How to cite: Pérez-Acebo, Heriberto; Salas, Miguel Ángel (2022). «Birziklatutako poliuretano-aparraren erabilera nahaste bituminosoetan»; Ekaia, ale berezia 2022, 75-89. (https://doi.org/10.1387/ekaia.23148).

Jasotze-data: 2021, urriak 30; Onartze-data: 2022, urtarrilak 7

ISSN 0214-9001 - elSSN 2444-3255 / (c) 2022 UPV/EHU
}

(c) (i) $(-)$ Lan hau Creative Commons Aitortu-EzKomertziala-LanEratorririkGabe 4.0 Nazioartekoa

(c) 


\section{SARRERA}

Gaur egun, adostasuna dago nazioartean garapen jasangarriaren beharraren inguruan, baliabide natural mugatuak modu eraginkorragoan kudea eta erabil daitezen, eta horrek hondakin-materialen birziklapena eta berrerabilera sustatzea barne hartzen du [1]. Oro har, baliabide naturalak hartu eta, hainbat eraldaketa-prozesuren ostean, azken produktu bihurtzen dira. Kontsumitu eta gero, gehienetan zabortegietan bukatzen dute, edo errausketa-instalazioetan erretzen dira, berrerabili beharrean [2]. Europar Batasunak baliabide-efikazia hobetzea eta ingurumen- eta klima-inpaktua murriztea ditu helburu, hondakinen berrerabilera eta birziklatzea sustatuz [3]. Hondakin batzuk produktu berean birziklatzen dira. Nolanahi ere, birziklatzeko tekniketan aurrera egin den arren, birziklatutako material batzuek ez dituzte kalitate-eskakizunak betetzen, eta, ondorioz, baztertu egiten dira.

Industriako azpiproduktu eta etxeko hondakin-material nagusietako bat plastikoak eta polimeroak dira gaur egun [4]. Hainbat prozesu gauzatzen dira horiek berrerabili eta birziklatzeko, hala nola birziklatze mekanikoa (prozesu mekanikoen bidez, bigarren mailako polimeroak lortzen dira), birziklatze kimikoa (monomeroak polimero birjina berri gisa erabiltzen dira, edo beste material erabilgarri batzuetan eraldatzen dira) eta berreskuratze energetikoa (erabili ondorengo plastikoen deskonposiziotik lortzen da energia) [5,6]. Gainera, material plastiko eta polimerikoen irtenbide posible bat bihurtzen ari da horiek beste materialetan betegarri bezala sartzea, batez ere eraikuntza-materialetan, hainbat material eraikitzailetan berrerabiltzeko, hala nola hormigoian [7], morteroetan [8], bide-zoruetako material bituminosoetan [9] eta igeltsuetan [10].

Plastiko eta polimeroei dagokienez, poliuretanoa hainbat aplikaziotan aurki daiteke: janari hotzaren katean, altzari eta koltxoietan, oinetakoetan, autoetan eta eraikinen isolatze termikoan. Normalean, poliuretanoak zabortegietan edo errausketa-instalazioetan amaitzen du, eta zati txiki bat (\% 10) bakarrik birziklatzen da. Indusketa-, eraikuntza- eta eraispen-hondakin kopuru handiarekin batera, Europar Batasuneko material guztiaren $\% 30$ da poliuretanoa [2]. Ondorioz, irtenbide bat bilatu behar da hondakin-produktu horien balioespena eta erabilera lortzeko.

Beroan egindako nahaste bituminosoak betunez, agregakin lodiz, agregakin finez eta hauts mineralez osatuta daude. Betuna da asfaltozko nahasteetan edo bituminosoetan osagai deformagarri bakarra, eta haien matrize jarraitua osatzen du [11]. Horrela, betunak tenperatura eta karga-tarte zabal batean dituen propietate biskoelastikoak ezaugarri giltzarri bat dira bide-zoruetako errendimenduari begira [12]. Bestalde, mastika bituminosoa nahaste trinko bat da, agregakin lodiz, agregakin finez (hondarra), hauts mineralez $(0,063 \mathrm{~mm}$ baino txikiagoa den materiala) eta betunez, eta agian osagai gehigarriz osatua [13]. Bere konposizioaren, aplikazioaren eta kar- 
ga-transferentziaren aldetik, ezberdina da beste nahaste bituminosoekin konparatuta. Bere konposizioari dagokionez, mastikaren osagai nagusiak hauek dira: lokailu bituminosoa - nahastearen masaren portzentajea \% 6tik $\%$ 9,5erako tartean, aplikazioaren arabera, eta batez beste $\% 8$ izanik - eta hauts minerala - masa osoaren \% 30etik gorako edukierarekin - . Horregatik, nahastearen \% 40 mastikatzat hartzen da (lokailua + hauts minerala), eta gainerako partea agregakin lodiek osatzen dute. Beroan egindako nahasteekin konparatuta, aldiz, azken horiek mastikaren \% 10-15 baino ez dira.

Hala ere, galtzada guztiak, hobekien diseinatuak eta eraikiak ere, hondatu egiten dira denboran zehar, trafiko-kargaren eta eguraldiaren ondorioz [14]. Hori dela eta, betunen errendimendua hobetzeko helburuarekin, eraldatzaile ugari analizatu dira [15]. Substantzia erabilienen artean, sufrea [16], azido polosforikoa [17], azido amido lodiak [18] eta polimeroak [19] nabarmen daitezke; polimerikoen artean, berriz, estireno butadieno estirenoa (SBS) eta binilazetato etilenoa eta poletilenoa [20].

Poliuretanoari dagokionez, poliuretano-apar itxuran, morteroetan [21], igeltsu arinetan [22] eta material bituminosoetan agregakinen ordezkari bezala [23] aztertu izan da. Zehazki, poliuretanoz eraldatutako betunen errendimendua analizatu da [24], baina, kasu honetan, polimeroa horretarako fabrikatu zen, eta ez hondakin-produktu bati bigarren erabilera bat emateko. Era berean, Carrera et al.-ek [25] emultsioetarako betun eraldatuaren erabilera aztertu zuten, baina polimeroa ez zen hondakin-produktu bat.

Horren ondorioz, eraldatutako betunaren bi nahaste bituminoso motetan poliuretano-aparraren erabilgarritasuna aztertzea da artikulu honen helburua: beroan egindako nahaste bituminoso batean eta mastika bituminoso batean; Marshall eta identazio-entseguen bidez, hurrenez hurren. Materialen propietateak aztertuko dira, araudiaren mugen barnean dauden eta/edo hobekuntzak sortzen diren ziurtatzeko.

\section{METODOLOGIA}

Programa esperimentala fase hauetan garatu zen:

a) Poliuretano-apar hondakina karakterizatzea.

b) Eraldatutako betunak diseinatu eta fabrikatzea, birziklatutako poliuretano-aparraren ehuneko ezberdinekin, bi nahaste bituminoso motetarako: beroan egindako nahaste bituminosorako eta mastika bituminosorako.

c) Eraldatutako betunen emaitzen arabera, emaitza onak ematen dituzten poliuretano-aparraren ehuneko handiena duten soluzioak aukeratzea. 
d) Aukeratutako ehunekoekin, bi nahaste bituminosoak diseinatu eta fabrikatzea, entseguak egitea eta emaitzak birziklatutako poliuretanoa ez daukaten laginekin konparatzea.

\section{MATERIALAK}

\subsection{Poliuretano-aparra}

Poliuretano-apar hondakina betun eraldatzaile bezala erabili zen. Eraikuntzan isolatzaile termiko gisa erabiltzen den poliuretanoaren fabrikazio-prozesuko azpiproduktu bat da. Materiala Burgoseko enpresa batek eman zuen. Hondakin horrek fabrikak sortutako poliuretanoaren pisu osoaren \% 5a baino gehiago suposatzen du. Poliuretano-aparra ez dagoenez hondakin arriskutsu gisa katalogatuta [26], azpiproduktu horretarako aplikazioak aurkitzea interes handikoa da, zabortegietan amai ez dezan. Hondakina xafla zurrun gisa jasotzen da fabrikatik, 1.a) irudian ikus daitekeen lez. Poliuretano-aparra txikitu egin zen, 0 eta $3 \mathrm{~mm}$ artean (1.b] irudia), 2. irudian erakusten den granulometria lortuz. Itxurazko dentsitatea $72 \mathrm{~kg} / \mathrm{m}^{3}$-koa da.
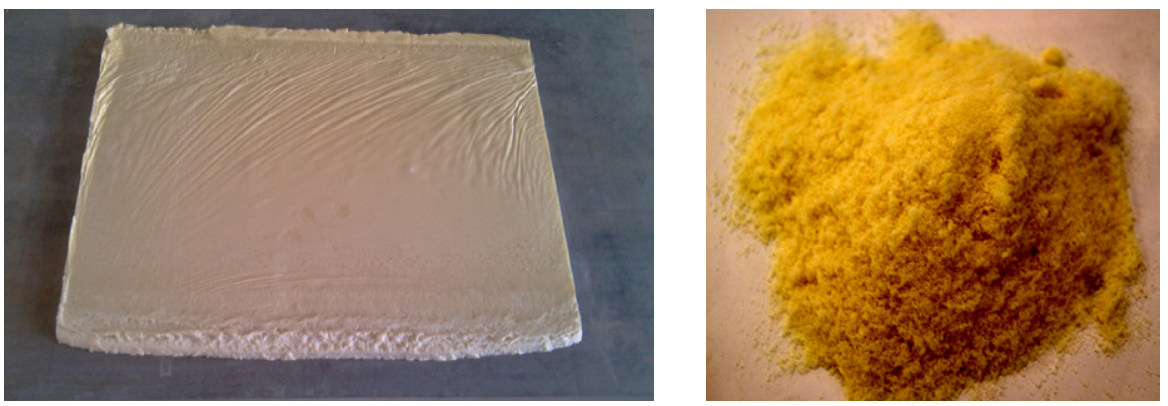

1. irudia. a) Poliuretano-aparraren zerrenda. b) Txikitutako poliuretano-aparraren itxura.
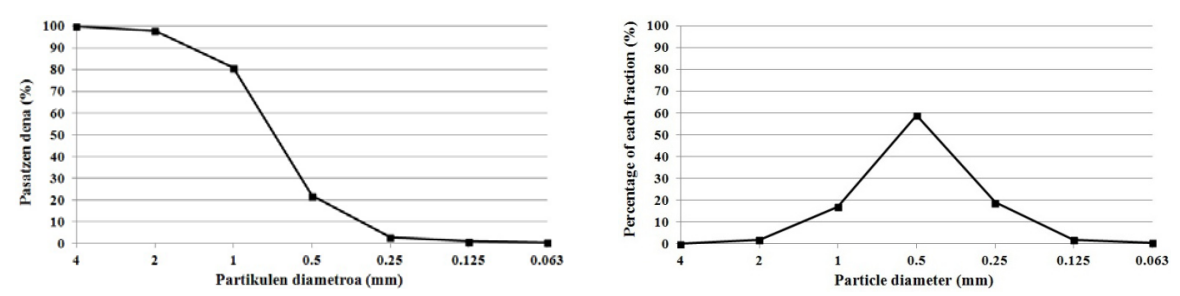

2. irudia. Txikitutako poliuretano-aparraren granulometria: a) pasatzen denaren ehunekoa, b) frakzio bakoitzaren ehunekoa. 


\subsection{Betuna}

Beroan egindako nahaste bituminosorako, B 50/70 barneratze-maila duen betun bat erabili zen eraldatutako betuna sortzeko. Espainiako araudiaren arabera [27], betun mota hau konbentzional bezala dago sailkatuta. Mastika bituminosorako, B 35/50 barneratze-mailako betuna erabili zen oinarrizko material bezala eraldatzeko. Balgorza SA izeneko enpresak hornitu zuen. Bi betunek 1. taulan erakusten diren eskakizunak betetzen dituzte.

1. taula. Betunek bete beharreko balioak.

\begin{tabular}{|c|c|c|c|c|c|}
\hline & Ezaugarria & Estandarra & Unitateak & $\begin{array}{l}50 / 70 \\
\text { betuna }\end{array}$ & $\begin{array}{c}35 / 50 \\
\text { betuna }\end{array}$ \\
\hline \multirow{2}{*}{\multicolumn{2}{|c|}{$\begin{array}{l}\text { Barneratzea } 25^{\circ} \mathrm{C} \text {-tan } \\
\text { Biguntze-puntua }\end{array}$}} & EN 1426 & $0,1 \mathrm{~mm}$ & $50-70$ & $35-50$ \\
\hline & & EN 1427 & ${ }^{\circ} \mathrm{C}$ & $46-54$ & $50-58$ \\
\hline \multirow{3}{*}{$\begin{array}{l}\text { Zahartzea } \\
\text { epe-laburrera } \\
\text { EN 12607-1 }\end{array}$} & Masa-aldaketa & EN 12607-1 & $\%$ & $\leq 0,5$ & $\leq 0,5$ \\
\hline & Mantendutako aldakuntza & EN 1426 & $\%$ & $\geq 53$ & $\geq 53$ \\
\hline & $\begin{array}{l}\text { Biguntze-puntuaren haz- } \\
\text { kundea }\end{array}$ & EN 1427 & ${ }^{\circ} \mathrm{C}$ & $\leq 10$ & $\leq 11$ \\
\hline \multirow{2}{*}{\multicolumn{2}{|c|}{ Barneratze-indizea }} & EN 12591 & & $-1,5$ etik & $-1,5$ etik \\
\hline & & EN 13924 & & $0,7 \mathrm{ra}$ & $0,7 \mathrm{ra}$ \\
\hline \multicolumn{2}{|c|}{ Fraass-en haustura-puntua } & EN 12593 & ${ }^{\circ} \mathrm{C}$ & $\leq-8$ & $\leq-5$ \\
\hline \multirow{2}{*}{\multicolumn{2}{|c|}{$\begin{array}{l}\text { Flash puntua, Cleveland cup metodoa } \\
\text { Disolbagarritasuna }\end{array}$}} & ISO 2592 & ${ }^{\circ} \mathrm{C}$ & $\geq 230$ & $\geq 240$ \\
\hline & & EN 12592 & $\%$ & $\geq 99,0$ & $\geq 99,0$ \\
\hline
\end{tabular}

\subsection{Agregakinak}

Birrindutako agregakin ofitikoak erabili ziren ikerketa honetan. Haro udalerrian (Espainia) dagoen Ofitas de San Felices harrobitik jaso ziren agregakinak. Beroan egindako nahaste bituminosorako, laginaren granulometriak gainazaleko (edo errodadurako) geruzaren nahaste gisa sailkatzeko eskakizunak bete ditu, bereziki AC 16 surf S izenekoa, Espainiako arauaren arabera [27]. AC 16 surf S izeneko nahaste bituminosoaren agregakinaren tamaina maximoa $16 \mathrm{~mm}$-koa da. Pisu espezifikoa $2,84 \mathrm{~g} / \mathrm{cm}^{3}$ da, Los Angeleseko abrasio-koefizientea 9,8 eta Pulimentutako Harriaren Balioa 57.

Mastika bituminosorako, $11 \mathrm{~mm}$-ko tamaina maximoko agregakina aukeratu zen (MA 11). Hauts minerala kareharri hautseztatua izan zen. Mastika bituminosoa erabiltzeko gainerako ezaugarri geometrikoen eskakizunak betetzen ziren [28]. 


\section{EMAITZAK ETA EZTABAIDA}

\subsection{Beroan egindako nahasteak}

Beroan egindako nahasteetarako, eraldatutako betun-ekoizpen polimeroa betun beroan $\left(>100{ }^{\circ} \mathrm{C}\right)$ sartu zen, ordubetez errotazio altuko errota batean ehotuz, polimeroa disolbatu eta nahasketa homogeneoa lortzeko. Erreferentziako betunetik abiatuta, zenbait betun eraldatu ekoiztu ziren poliuretano-apar hondakina hainbat ehunekotan gehituz, \% 1etik \% 5era bitartean, betunaren pisuarekiko. Polimeroaren ehunekoak betunaren pisuaren proportzioa adierazten du pisuan. 2. taulak landutako aleak eta birziklatutako aparraren portzentajeak erakusten ditu. Poliuretano-aparren ordezkapenak \% 5eko edo gehiagoko kopuruan errefusatu ziren, eraldatutako nahasteak materialaren langarritasun baxuegia ekartzen zuelako.

Betun guztien karakterizazioa, $25^{\circ} \mathrm{C}$-ko barneratze-mailarekin eta biguntze-puntuko tenperaturarekin, eraztun eta bola (B\&R) metodoaren bidez zehaztu zen. Betunei eragindako barneratze-probak (2. taula) baieztatu zuen poliuretano-aparraren portzentajea handitu ahala, zifrak baxuagoak zirela, hau da, eraldatutako betuna gogortu egiten zela polimero kopurua handitu ahala. Eraztun eta bolaren entseguak ziurtatu zuen polimero gehiago erantsi ahala, biguntze-puntuaren tenperatura handitu egiten dela (2. taula).

2. taula. Ekoiztutako polimeroz eraldatutako betunak, beroan egindako nahaste bituminosoetarako.

\begin{tabular}{clcc}
\hline Lagina & \multicolumn{1}{c}{ Ezaugarria } & $\begin{array}{c}\text { Barneratze-balioa } \\
\left(10^{-1} \mathrm{~mm}\right)\end{array}$ & $\begin{array}{c}\text { Biguntze-puntuaren } \\
\text { tenperatura }\left({ }^{\circ} \mathrm{C}\right)\end{array}$ \\
\hline B & Erreferentziako betuna B50/70 & 55 & $48 / 52$ \\
BM1 & Eraldatutako betunaren \% 1 poliuretano-aparra & 47 & $52 / 55$ \\
BM2 & Eraldatutako betunaren \% 2 poliuretano-aparra & 46 & $52 / 54$ \\
BM3 & Eraldatutako betunaren \% 3 poliuretano-aparra & 44 & $53 / 56$ \\
BM4 & Eraldatutako betunaren \% 4 poliuretano-aparra & 43 & $62 / 66$ \\
\hline
\end{tabular}

Lehen esan den bezala, material bituminosoetan polimeroen gehikuntzarekin lortzen diren propietateak material organiko horien izaeraren eta egitura kimikoaren araberakoak dira. Oro har, material horien kate luzeek elastikotasun handiagoa ematen diote nahasteari, polimero-kate oso luzeak daudelako. Polimeroetan kate laburrak ere badaude, eta horiek hobetu egiten dute agregakinekiko atxikimendua. Aldi berean, polimero-kateen lotura fisiko bat sortzen da fase ezberdinen artean, nahasteen kohesioa indartzen duena eta gehitutako polimeroaren pisu molekularraren eta biskositatearen araberakoa dena. 
Aipatutako agregakina erabiliz, bide-zoruetako errodadura-geruzetarako sailkatuta dagoen AC 16 surf S [27]-ren bi lagin sorta prestatu ziren, bakoitza 3 probetekin (3. irudia).

- A seriea: B 50/70 betun orijinala duten laginak.

- B seriea: BM4 betuna duten laginak. Ikerketapean zeuden betunen artean, BM4 betuna aukeratu zen, hondakin kopuru handiena duena delako, gogortasunerako eta biguntze-puntuaren tenperaturako propietate onargarriak mantenduz.

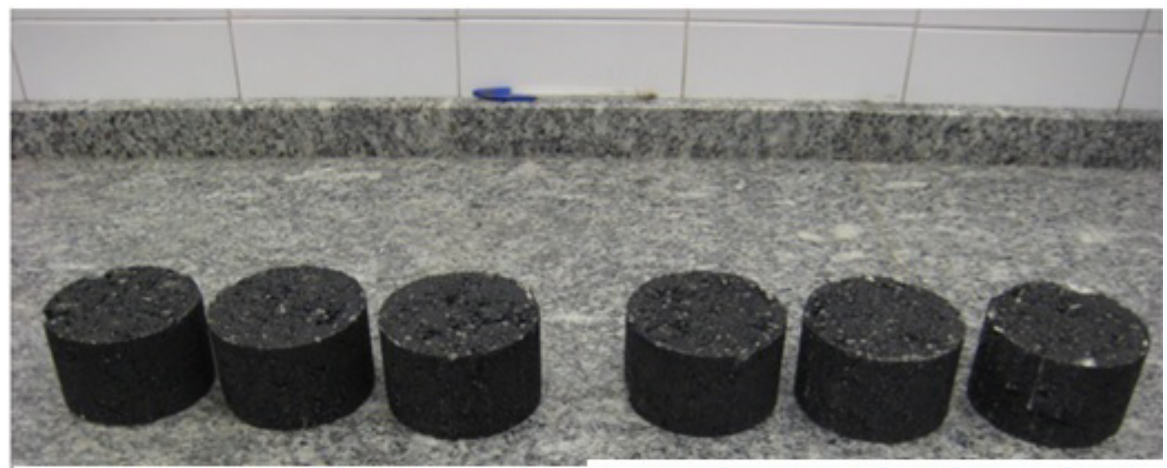

SERIE A (B 50/70 betunarekin) SERIE B (BM4 betunarekin)

3. irudia. AC 16 surf S laginak, B50/70 betunarekin eta eraldatutako BM4 betunarekin eginak.

Serie bietarako nahaste bituminosoak betunaren $\% 4,8$ ko portzentajearekin prestatu ziren. Serie bakoitzaren itxurazko dentsitate espezifikoa eta dentsitate espezifiko teorikoa EN 12697-6 [29] arauan definitutako prozedura lehorraren bitartez determinatu ziren, 3. taulan erakusten den bezala.

3. taula. Entseguen emaitzak A eta B serieetarako.

\begin{tabular}{lrrc}
\hline \multicolumn{1}{c}{ Ezaugarriak (unit.) } & A seriea & B seriea & $\begin{array}{c}\text { Hazkundea B seriean } \\
\text { A seriearekiko (\%) }\end{array}$ \\
\hline Egonkortasuna (kp) & 1.672 & 2.037 & $+21,86$ \\
Deformazioa (mm) & 3,14 & 2,03 & $-35,35$ \\
Hutsuneak nahastean, Vm (\%) & 5,20 & 5,80 & 11,54 \\
Hutsuneak agregakinetan, VMA (\%) & 17,10 & 17,40 & 1,75 \\
Agregakinen hutsuneak betunez beteta (\%) & 69,40 & 66,60 & $-4,03$ \\
Nahastearen itxurazko dentsitatea $\left(\mathrm{kg} / \mathrm{m}^{3}\right)$ & 2.491 & 2.479 & $-0,48$ \\
Nahastearen dentsitate teorikoa $\left(\mathrm{kg} / \mathrm{m}^{3}\right)$ & 2.628 & 2.631 & 0,11 \\
\hline
\end{tabular}


3. taulan ikus daitekeen bezala, Marshall entseguetan lortutako emaitzek erakusten dute poliuretano-aparra duen nahasketak egonkortasun handia izan duela, eta murrizketa handia eragin duela deformazioan. Nahaste horiek goranzko kargei aurre egin ahal izatea iradokitzen dute. Nolanahi ere, aire-hutsuneen portzentajea handitu egiten da, eta horrek nahastearen errendimendu txarragoa ekar dezake. Balio hori, hala ere, Espainiako araudiak edozein trafiko-kategoriako errodadura-geruzetarako (4. taula) ezarritako mugaren azpitik dago oraindik [27]. Beraz, gehiketak ez luke eraginik izango nahaste bituminosoen zahartze-prozesuan. Gainera, nahastearen langarritasuna ziurtatuta dago gehitutako polimeroaren portzentajearen bitartez, eta suposa daiteke obran zabaltzea eta trinkotzea onargarria izango dela, polimeroaren eragin lubrifikatzailearen ondorioz.

4. taula. Ekoiztutako polimeroz eraldatutako betunetan onartzen diren aire-hutsuneak, trafiko-kategoriaren eta zabaltzen den geruzaren arabera [27].

\begin{tabular}{|c|c|c|c|c|c|}
\hline \multirow{2}{*}{ Ezaugarria } & \multirow{2}{*}{ Geruza } & \multicolumn{4}{|c|}{ Trafiko astunaren kategoria } \\
\hline & & $\mathrm{T} 00$ eta $\mathrm{T} 0$ & $\mathrm{~T} 1$ eta $\mathrm{T} 2$ & $\mathrm{~T} 3$ & $\mathrm{~T} 4$ \\
\hline \multirow{3}{*}{$\begin{array}{c}\text { Aire-hutsuneak } \\
(\%)\end{array}$} & Errodadura-geruza & \multicolumn{2}{|c|}{$4-6$} & \multicolumn{2}{|c|}{$3-6$} \\
\hline & Tarteko geruza & $4-6$ & $4-7$ & $4-7$ & $4-7$ \\
\hline & Oinarrizko geruza & $4-7$ & $4-8$ & $4-8$ & \\
\hline
\end{tabular}

\subsection{Mastika bituminosoa}

Era berean, erreferentziako betunari (B 35/50) poliuretano-hondakinaren hainbat kantitate gehituz prestatu ziren mastika bituminosoa sortzeko erabiliko diren eraldatutako betunak. Gehitutako ehunekoak betunaren masaren \% 1etik \% 5era bitartekoak izan ziren. Katalizatzailerik gabe, baztertu egin ziren gehitutako portzentajea \% 5etik gora zuten nahasketak, eraldatutako betuna material zakar bihurtzen baitzen, langarritasun eskasekoa. Arazo hori saihets liteke erreaktibo edo aurrepolimero bat gehituz, beste egile batzuek egin duten moduan [30, 31]. Hala ere, kasu honetan, erreaktibo edo aurrepolimerorik gehitu gabe aztertu nahi zen.

Erreferentziako betunaren eta eraldatutako betunaren karakterizazioa $25^{\circ} \mathrm{C}$-ko barneratze-mailaren eta biguntze-puntuaren tenperaturaren bidez egin zen, eraztun eta bola metodoari jarraituz. Barneratze-entseguen emaitzak 5. taulan daude. Ikusten den bezala, birziklatutako poliuretanoaren ehuneko handiago bat gehituta, balioak baxuagoak ziren. Horrek adierazten du eraldatutako betuna gogortu egiten dela polimero gehiago erabiltzean. Era berean, biguntze-puntua igo egiten da, polimero gehiago erantsi ahala (5. taula). 
5. taula. Ekoiztutako polimeroz eraldatutako betunak.

\begin{tabular}{clcc}
\hline Lagina & \multicolumn{1}{c}{ Ezaugarriak } & $\begin{array}{c}\text { Barneratze-balioa } \\
\left(10^{-1} \mathrm{~mm}\right)\end{array}$ & $\begin{array}{c}\text { Biguntze-puntuaren } \\
\text { tenperatura }\left({ }^{\circ} \mathrm{C}\right)\end{array}$ \\
\hline B & Erreferentziazko betuna (B 35/50) & 41 & 53,5 \\
BM1 & Eraldatutako betunaren \% 1 poliuretano-aparra & 34 & 56,5 \\
BM2 & Eraldatutako betunaren \% 2 poliuretano-aparra & 33 & 57,5 \\
BM3 & Eraldatutako betunaren \% 3 poliuretano-aparra & 31 & 58,0 \\
BM4 & Eraldatutako betunaren \% 4 poliuretano-aparra & 29 & 65,5 \\
\hline
\end{tabular}

Barneratze- eta biguntze-puntuaren entseguen emaitzak mota honetako betunen ohiko mugen artean daudenez, mastika bituminosoaren ekoizpenerako eta ebaluaziorako \% 4ko betuna aukeratu zen, bere gogortasun handiagoagatik eta hondakin-materialen portzentaje altuagogatik.

Mastika bituminosozko bi ale fabrikatu ziren. Lehena, N11 Normal izenekoa, inolako polimero gehigarririk gabe ekoiztu zen, eta erreferentzia bezala erabili zen. Bigarrena, N11 PUR izenekoa, entseguen arabera, betunaren $\%$ an poliuretano-aparra zuela gauzatu zen. Europako EN 13108-6 [28] estandarrari jarraituz ekoiztu ziren bi kasuetan. Bi laginetan erabilitako granulometriak 6. taulan agertzen dira, EN 13108-6 estandarraren eskakizunak betez [28]. N11 Normal eta N11 PUR laginetako osagarri bakoitzaren portzentajeak 7 . taulan zerrendatzen dira.

6. taula. Mastika bituminosoetan erabilitako granulometriak (N11 Normal eta N11 PUR) (pasa den \%).

\begin{tabular}{l|cccccccc}
\hline \multirow{2}{*}{ Lagina } & \multicolumn{8}{|c}{ Bahea $(\mathrm{mm})$} \\
\cline { 2 - 9 } & 11,2 & 8 & 5,6 & 4 & 2 & 0,5 & 0,25 & 0,063 \\
\hline N11 Normal & 100 & 100 & 100 & 86 & 57 & 41,3 & 36 & 28,1 \\
N11 PUR & 100 & 100 & 100 & 81 & 56 & 41,0 & 36 & 27,4 \\
\hline
\end{tabular}

7. taula. Ekoiztutako mastika bituminosozko laginen datuak.

\begin{tabular}{lcccc}
\hline \multicolumn{1}{c}{ Lagina } & $\begin{array}{c}\text { Ekoizteko } \\
\text { tenperatura }\end{array}$ & $\begin{array}{c}\text { Lokailu/Agregakinak } \\
(\%)\end{array}$ & $\begin{array}{c}\text { Hauts minerala/ } \\
\text { Betuna }\end{array}$ & $\begin{array}{c}\text { Dentsitatea } \\
\left(\mathrm{g} / \mathrm{cm}^{3}\right)\end{array}$ \\
\hline N11 Normal & 230 & 8,43 & 3,30 & 2.420 \\
N11 PUR & 230 & 8,70 & 3,10 & 2.404 \\
\hline
\end{tabular}

Indentazio-entsegua, Gogortasun-zenbakiarekin batera, mastika bituminosoei buruzko Europako estandarrean erreferentziazko entsegu gisa eza- 
rrita dago, deformazio iraunkorrari aurre egiteko materialaren gaitasuna irudikatzeko. Mastika bituminosoari buruzko Espainiako estandarren arabera [32], bost indentazio-entsegu desberdin daude, mastika bituminosoa non aplikatuko den (8. taula). 9. taulak mastikaren aplikazio bakoitzerako egin beharreko indentazio-entseguak eta entseguetan lortu beharreko balioak erakusten ditu.

8. taula. Indentazio-entseguak, mastika bituminosoetan aplikatzeko [32].

\begin{tabular}{|c|c|c|c|c|c|}
\hline & $\begin{array}{c}\text { W } \\
\text { entsegua }\end{array}$ & A entsegua & B entsegua & C entsegua & $\begin{array}{c}\text { D } \\
\text { entsegua }\end{array}$ \\
\hline Tenperatura $\left({ }^{\circ} \mathrm{C}\right)$ & 25 & 25 & 40 & 40 & 22 \\
\hline Markaren azalera & $31,7 \mathrm{~mm}^{2}$ & $5 \mathrm{~cm}^{2}$ & $5 \mathrm{~cm}^{2}$ & $1 \mathrm{~cm}^{2}$ & $1 \mathrm{~cm}^{2}$ \\
\hline Aplikatutako karga (kg) & 31,7 & 52,5 & 52,5 & 52,5 & 52,5 \\
\hline Karga aplikatzeko denbora & $\begin{array}{l}1 \text { minutu } \\
\text { eta } 10 \text { segundo }\end{array}$ & 6 minutu & 31 minutu & 31 minutu & 300 minutu \\
\hline Neurketa tartea & $\begin{array}{l}10 \text { segundo- } \\
70 \text { segundo }\end{array}$ & $\begin{array}{l}1 \mathrm{~min}- \\
6 \mathrm{~min}\end{array}$ & $\begin{array}{l}1 \mathrm{~min}- \\
31 \mathrm{~min}\end{array}$ & $\begin{array}{l}1 \mathrm{~min}- \\
31 \mathrm{~min}\end{array}$ & $\begin{array}{l}1 \text { min- } \\
300 \text { min }\end{array}$ \\
\hline
\end{tabular}

9. taula. Aplikazio bakoitzerako erabilitako indentazio-entsegua eta lortu beharreko balioak.

\begin{tabular}{lcccc}
\hline \multicolumn{1}{c}{ Aplikazioa } & $\begin{array}{c}\text { Erreferentziako } \\
\text { izena }\end{array}$ & $\begin{array}{c}\text { Aplikatutako } \\
\text { indentazio-entsegua }\end{array}$ & $\begin{array}{c}\text { Ohiko } \\
\text { geruzen } \\
\text { lodiera } \\
(\mathrm{mm})\end{array}$ & $\begin{array}{c}\text { Lortu beharreko } \\
\text { indentazio-balioa } \\
\left(10^{-1} \mathrm{~mm}\right)\end{array}$ \\
\hline Oinezkoentzako eremuak & AP & B entsegua & $20-25$ & $20 \leq \mathrm{I} \leq 50$ \\
\hline Errepideak & AVL & B entsegua & $25-30$ & $10 \leq \mathrm{I} \leq 30$ \\
\hline Trafiko astuneko errepideak & AVP & B entsegua & $30-40$ & $5 \leq \mathrm{I} \leq 15$ \\
\hline $\begin{array}{l}\text { Etxebizitzen zorua isolatze } \\
\text { akustikoa }\end{array}$ & AIP & C entsegua & & $1 \leq \mathrm{I} \leq 12$ \\
\hline $\begin{array}{l}\text { Industrietako barruko zoruak } \\
\text { Karga handiko industrietako } \\
\text { barruko zoruak }\end{array}$ & AIC & C entsegua & $25-30$ & $10 \leq \mathrm{I} \leq 30$ \\
\hline $\begin{array}{l}\text { Azidoen aurkako zoruak } \\
\text { Kirol-guneak }\end{array}$ & C entsegua & $25-30$ & $1 \leq \mathrm{I} \leq 12$ \\
\hline
\end{tabular}

Ikerketa honetan errepideetan erabiltzeko mastika bituminosoa ikertu nahi zenez, B indentazio-entsegua egin zen. N11 Normal laginetan bi proba 
egin ziren, eta N11 PUR laginetan lau proba. Emaitzak 10. taulan erakusten dira. N11 Normal laginaren emaitzak N11 PUR laginarenak baino homogeneoagoak dira. Hala ere, agerian geratzen da eraldatutako mastikan indentazio-balio baxuagoak lortzen direla. 9. taularen arabera, N11 PUR mastika bituminosoa trafiko astuna duten errepideetan erabil daiteke, nahastearen propietate mekanikoak hobetzearen ondorioz.

10. taula. Indentazio-entseguan lortutako emaitzen laburpena.

\begin{tabular}{c|lccc}
\hline \multicolumn{2}{c}{ Lagina } & $\begin{array}{c}\text { Indentazio-sakonera } \\
\text { minutu batean } \\
\left(10^{-1} \mathrm{~mm}\right)\end{array}$ & $\begin{array}{c}\text { Indentazio-sakonera } \\
31 \text { minututan } \\
\left(10^{-1} \mathrm{~mm}\right)\end{array}$ & $\begin{array}{c}\text { Indentazio-balioa } \\
\left(10^{-1} \mathrm{~mm}\right)\end{array}$ \\
\hline \multirow{3}{*}{ N11 } & 1. entsegua & 20,2 & 41,0 & 20,80 \\
Normala & 2. entsegua & 15,8 & 34,3 & 18,50 \\
& Batezbestekoa & & & 19,65 \\
\hline \multirow{3}{*}{ N11 } & 1. entsegua & 7,3 & 20,4 & 13,10 \\
PUR & 2. entsegua & 16,2 & 30,8 & 14,60 \\
& 3. entsegua & 22,3 & 34,6 & 12,30 \\
& 4. entsegua & 19,9 & 38,9 & 19,00 \\
& Batezbestekoa & & & 14,75 \\
\hline
\end{tabular}

Poliuretano-aparra sartzearen ondorioz, indentazio-balioaren murrizketa garrantzitsu bat lortu zen, \% 19,65etik \% 14,75era (-\% 24,9), eta horrek aukera ematen du eraldatutako mastika trafiko handiko errepideetan erabiltzeko. Gainera, dentsitatearen aldakuntza txiki bat hautematen da (7. taula). Hori dela eta, poliuretano-aparra erabiltzeko aukera balidatu egin da entsegu hauen bidez. Material berriak hobetu egiten du karga aplikatuen aurreko errendimendua, ikerketaren bi helburu nagusiak lortuz: hondakinak gutxitzen laguntzea eta, aldi berean, materialaren ezaugarriak hobetzea.

\section{ONDORIOAK}

Artikulu honetan, betun eraldatzaile gisa poliuretano-apar azpiproduktuak duen erabilgarritasunari buruzko aldez aurreko emaitzak aurkezten dira beroan egindako nahaste bituminosoetan eta mastika bituminosoetan.

Beroan egindako nahaste bituminosoak prestatzean, birziklatutako polimeroaren hainbat portzentajetako bost betun-lagin produzitu ziren, betunaren masaren $\% 1, \%$ 2, \% 3, \% 4 eta $\% 5$ ordezkatuz, B 50/70 motako betun original batetik. Gogortasun handiagoa eta biguntze-puntuaren tenperatura 
baxuagoa nabaritu ziren portzentajea handitu heinean. Poliuretanoa $\%$ ean zuen laginarekin, betuna zakartu egiten zela eta bere langarritasuna murriztu egiten zela ikusi zen. Hori dela eta, poliuretanoa \% 4an duen lagina hautatu zen nahaste bituminosoa fabrikatzeko.

Marshall entseguan lortutako emaitzek erakutsi zuten polimero-aparraren bidez eraldatutako betuna zuen nahasteak hobekuntza handia zuela egonkortasunaren aldetik. Bestalde, aire-hutsuneen kopuru altuagoak errendimendu txarragoa iradoki ahal izan arren, aire-hutsuneen kopuruaren balioa Espainiako arauen balio onargarrien artean dago, edozein trafiko kategoriatan.

Mastika bituminosoan, betun gogorragoa lortu zen poliuretano-hondakinaren kopurua handitu ahala, betunaren masaren pisuaren \% 1etik \% 4ra. Poliuretanoa \% 5ean edo gehiagoan zuten laginak baztertu egin ziren, beren langarritasun eskasagatik. Emaitza horien ondorioz, poliuretano-aparra \% 4an zeukan betuna aukeratu zen mastika bituminosoa ekoizteko eta polimerorik gabeko betuna zuen beste mastikarekin konparatzeko. Eraldatutako betuna zuen laginaren propietate mekanikoak hobetu egin ziren, indentazio-entseguan islatu zen bezala. Eraldatutako betuneko lagina trafiko normaleko errodadura-geruzetan erabiltzeko aproposa zen arren, eraldatutako betuneko laginak hobetu egin zituen emaitzak, egokia baitzen trafiko normal eta astuneko errodadura-geruzetarako. Ia \% 25eko hobekuntza lortu zen indentazio-balioetan, dentsitatean aldaketarik izan gabe. Hurrengo pausoa azterlan oso bat egitea izango litzateke, entsegu guztiak bi nahaste bituminoso motetan aplikatuz.

Ondorio gisa, esan daiteke birziklatutako poliuretano-aparra, eraikuntza-industriako azpiproduktu bat dena, etorkizun handiko materiala dela betun eraldatzaile gisa erabiltzeko, bai beroan egindako nahasteetan, bai mastika bituminosoetan.

\section{BIBLIOGRAFIA}

[1] Pérez, I., Toledano, M., Gallego, J., Taibo, J. 2007. «Mechanical properties of hot mix asphalt made wth recycled aggregates from reclaimed construction and demolition debris». Materiales de Construcción, 57(285), 17-29.

[2] Poulikakos, L.D., Papadaskalopoulou, C., Hofko, B., Gschösser, F., Cannone Falchetto, A., Bueno, M., Arraigada, M., Sousa, J., Ruiz, R., Petit, C., Loizidou, M., PARTi, M. N. 2017. «Harvesting the unexplored potential of European waste materials for road construction». Resources, Conservation and Recycling, 116, 32-44.

[3] European Parliament. 2008. European waste framework directive 2008/98/ $E G$. Brussels, Belgium. 
[4] Aumnate, C., Rudolph, N., Sarmadi, M. 2019. «Recycling of polypropylene/polyethylene blends: Effects of chain structure on the crystallization behaviors». Polymers, 11, 1456.

[5] Kiss, G., Rusu, G., Peter, F., Tanase, I., Bandur, G. 2020. «Recovery of flexible polyurethane foam waste from efficient reuse in industrial formulations». Polymers, 12, 1533.

[6] Ungureanu, O. I., Bulgariu, D., Mocanu, A. M., Bulgariu, L. 2020. «Functionalized PET waste based low-cost adsorbents for adsorptive removel od CU(II) ions from aqueous media». Water, 12, 2624.

[7] Siddique, R., Khatib, J., Kaur, I. 2008. «Use if recycled plastic in concrete: A review». Waste Management, 28, 1835-1852.

[8] FARINHA, C. B., De Brito, J., Beiga, R. 2019. «Assessment of glass fiber reinforced polumer wste reuse as filler in mortars». Journal of Cleaner Production, 210, 1579-1594.

[9] Hassani, A., Ganjidoust, H., Maghanaki, A. A. 2005. «Use of plastic waste (polyethylene terephthalate) in asphalt concrete mixture as aggregate replacement». Waste Management and Resource, 23, 322-327.

[10] Alameda, L., Calderón, V., Junco, C., Rodríguez, A., Gadea, J., GutiéRREZ-GONZÁLEZ, S. 2016. «Characterization of gypsum plasterboard with polyurethane foam waste reinforced with polyproylene fibers». Materiales de Construcción, 66, 100.

[11] Adedej, A., Grünfelder, T., Bates, F. S., Macosko, C. W., Stroup-GarDINER, M., NEWCOMB, D. E. 1996. «Asphalt modified with SBS triblock copolymer: structures properties». Polymer Engineering \& Science, 36(12), 1707-1723.

[12] Vasiljevic-Shikaleska, A., Popovska-Pavlovska, F., Cimmino, S., DuRACCIO, D., SilveSTRE, C. 2010. «Viscoelastic properties and morphological characteristics of polumer modified bitumen blends». Journal of Applied Polymer Science, 118(3), 1320-1330.

[13] International Mastic Asphalt Association (IMMA). 2013. The Mastic Asphalt Industry. A global perspective. International Mastic Asphalt Association, Bern, Switzerland.

[14] Pérez-Acebo, H., Mindra, N., Railean, A., Rojí, E. 2019. «Rigid pavement performance models by means of Markov Chains with half-year step time». International Journal of Pavement Engineering, 20(7), 830-843.

[15] Bahia, H. U., Hislop, W. P., Zhai, H. Rangel, A. 1998. «Classification of asphalt binders into sample and complex binders». Journal of the Association of Asphalt Paving Technologists, 67, 1-41.

[16] Smagulova, N., Kairbekov, Z., Aubakorov, E., Yermoldina, E. 2012. «Production of bitumens from coal sources modified by elementary sulfur». Advanced Materials Research, 535, 1815-1818.

[17] Masson, J. F. 2008. «Brief review of the chemistry of polyphosphoric adic (PPA) and bitumen». Energy \& Fuel, 22(4), 2637-2640. 
[18] Senior-Arrieta, V., Córdoba-Maquilón, J. E. 2017. «Mechanical characterization of porous asphalt mixes with fatty acid amides - FFA -». Ingeniería e Investigación, 37(1), 43-48.

[19] Navarro, F. J., Partal, P., Martínez-Boza, F., Gallegos, C. 2004. «Thermo-rheological behaviour and storage stability of ground tire rubber-modified bitumen». Fuel, 83(14), 2041-2049.

[20] Wu, S., Montalvo, L. 2021. «Repurposing waste plastics into cleaner asphalt pavement materials: A critical literature review». Journal of Cleaner Production, 280, 124355.

[21] Junco, C., Gadea, J., Rodríguez, A., Gutiérrez-González, S., Calderón, V. 2012. «Durability of lightweight masonry mortarts made with white recycled polyurethane foam». Cement and Concrete Composites, 34(10), $1174-$ 1179.

[22] Gutiérrez-González, S., Gadea, J., Rodríguez, A., Junco, C., CAlderón, V. 2012. «Lightweight plaster materials with enhanced thermal properties made with polyurethane foam wastes». Construction \& Building Materials, 28(1), 653-658.

[23] Tribout, C. Husson, B. 2010. «Use of treated sediments in road building techniques». European Journal of Environmental and Civil Engineering, 15(2), 197-213.

[24] Izquierdo, M. A., Navarro, F. J., Martínez-Boza, F. J. Gallegos, C. 2012. «Bituminous polyurethane foam for building applications: Influence of bitumen hardness». Construction \& Building Materials, 30, 706-713.

[25] Carrera, V., Cuadri, A. A., García-Morales, M., Partal, P. 2015. «The development of polyurethane modifed bitumen emulsions for cold mix applications». Materials and Structures, 48(10), 3407-3414.

[26] Ministerio de Medio Ambiente 2002. Orden MAM/304/2002, de 8 de febrero, por la que se publican las operaciones de valorización y eliminación de residuos y la lista europea de residuos. BOE, núm. 46, de 19 de febrero de 2002, 6494-6515. Gobierno de España, Madrid.

[27] Ministerio de Fomento. 2015. Orden FOM/2523/2014, de 12 de diciembre, por la que se actualizan determinados artículos del pliego de prescipciones técnicas generales para obras de carreteras y puentes, relativos a materiales básicos, a firmes y pavimentos, y a señalización, balizamiento y sistemas de conteción de vehiculos. Gobierno de España, Madrid.

[28] CEN-European Committee for Standardization. 2016. EN 13108-6: Bituminous mixtures - amterial specifications - Part 6: Mastic asphalt. CENEuropean Committee for Standardization, Brussels, Belgium..

[29] CEN-European Committee for Standardization. 2005. EN 12697-6. Bituminous mixtures - Test methods for hot mix asphalt - Parte 6: Determination of buld density of bituminous specimens. CEN-European Committee for Standardization, Brussels, Belgium. 
[30] Singh, B., GuPTA, M, Kumar, L. 2006. «Bituminous polyurethane network: preparation, properties and end use». Journal of Applied Polymer Science, 101, 217-226.

[31] Carrera, V., Partal, P., García-Morales, M., Gallegos, C., Pérez-Lepe, A. 2010. «Effect of processin on the rheological properties of polyurethane/ urea bituminous products». Fuel Processing Technology, 91, 1139-1145.

[32] Asociación Nacional del Asfalto Fundido (ASNAFU). 2010. Prescripciones y técnicas comunes a los asfaltos fundidos. Edición 1. ASNAFU, Madrid, Spain. 
